\title{
Mycoremediation of Benzo[a]pyrene by Pleurotus ostreatus in the presence of heavy metals and mediators
}

\author{
Sourav Bhattacharya $\cdot$ Arijit Das $\cdot$ \\ Kuruvalli Prashanthi · Muthusamy Palaniswamy • \\ Jayaraman Angayarkanni
}

Received: 10 April 2013/ Accepted: 25 May 2013/Published online: 7 June 2013

(C) The Author(s) 2013. This article is published with open access at Springerlink.com

\begin{abstract}
Benzo $[a]$ pyrene is considered as a priority pollutant because of its carcinogenic, teratogenic and mutagenic effects. The highly recalcitrant nature of Benzo $[a]$ pyrene poses a major problem for its degradation. White-rot fungi such as Pleurotus ostreatus can degrade Benzo $[a]$ pyrene by enzymes like laccase and manganese peroxidase. The present investigation was carried out to determine the extent of Benzo $[a]$ pyrene degradation by the PO-3, a native isolate of $P$. ostreatus, in the presence of heavy metals and ligninolytic enzyme mediators. Modified mineral salt medium was supplemented with $5 \mathrm{mM}$ concentration of different heavy metal salts and ethylenediaminetetraacetic acid. Vanillin and 2,2'-azinobis-(3ethylbenzothiazoline-6-sulfonate) (1 and $5 \mathrm{mM}$ ) were used to study the effect of mediators. Results indicated that $P$. ostreatus PO-3 degraded $71.2 \%$ of Benzo[a]pyrene in the presence of copper ions. Moderate degradation was observed in the presence of zinc and manganese. Both biomass formation and degradation were severely affected
\end{abstract}

S. Bhattacharya $(\bowtie) \cdot$ M. Palaniswamy

Department of Microbiology, Karpagam University,

Coimbatore 641021, Tamil Nadu, India

e-mail: sourav3011@rediffmail.com

\section{A. Das}

Department of Microbiology, Genohelix Biolabs,

Centre for Advanced Studies in Biosciences, Jain University,

Bangalore 560019, Karnataka, India

K. Prashanthi

Department of Biotechnology, Genohelix Biolabs,

Centre for Advanced Studies in Biosciences, Jain University,

Bangalore 560019, Karnataka, India

J. Angayarkanni

Department of Microbial Biotechnology, Bharathiar University,

Coimbatore 641046, Tamil Nadu, India in the presence of all other heavy metal salts used in the study. Copper at $15 \mathrm{mM}$ concentration supported the best degradation $(74.2 \%)$, beyond which the degradation progressively reduced. Among the mediators, $1 \mathrm{mM}$ 2,2'-azinobis-(3-ethylbenzothiazoline-6-sulfonate) supported $78.7 \%$ degradation and $83.6 \%$ degradation was observed under the influence of $5 \mathrm{mM}$ vanillin. Thus, metal ion like copper is essential for better biodegradation of Benzo[a] pyrene. Compared to synthetic laccase mediator like 2,2'-azinobis-(3-ethylbenzothiazoline-6-sulfonate), natural mediator such as vanillin may play a significant role in the degradation of aromatic compounds by white-rot fungi.

Keywords Benzo[a]pyrene - Pleurotus ostreatus . Degradation $\cdot$ Heavy metals $\cdot$ Mediators

\section{Introduction}

Benzo $[a]$ pyrene $(\mathrm{B} a \mathrm{P})$, a representative of high molecular weight polycyclic aromatic hydrocarbon (HMW PAH), consists of five fused benzene rings and is of environmental concern since it behaves as a potent teratogen, mutagen and carcinogen. Its high molecular weight and extremely low water solubility reduce its bioavailability, thus making it resistant to microbial degradation (Rentz et al. 2008). Together with other PAHs, $\mathrm{B} a \mathrm{P}$ is commonly formed under natural conditions like volcanic eruptions and forest fires and by anthropogenic activities like the pyrolysis and incomplete combustion of fossil fuels ( $\mathrm{Li}$ et al. 2009).

Different strategies for removal of $\mathrm{B} a \mathrm{P}$ and other highly recalcitrant compounds from contaminated sites include chemical oxidation, photolysis and biodegradation. Among all these clean up strategies, involvement of microorganisms is a subject of intense research and gains a cutting 
edge advantage for being less expensive and environment friendly (Chatterjee et al. 2008).

In nature there exists a great diversity of microorganisms capable of PAH degradation. Bacteria are capable of degrading the low molecular weight $\mathrm{PAH}$, such as naphthalene, acenaphthene and phenanthrene and relatively few genera have been observed to degrade the HMW PAHs, such as $\mathrm{B} a \mathrm{P}$ (Juhasz and Naidu 2000). However, several white-rot fungi (Phanerochaete chrysosporium, Coriolus versicolor, Stropharia coronilla, Pleurotus ostreatus, Irpex lacteus and Bjerkandera adusta) that synthesizes extracellular lignin modifying enzymes like lignin peroxidases (LiP), manganese peroxidases (MnP), laccases and other oxidases can oxidize $\mathrm{B} a \mathrm{P}$ and similar HMW PAHs with up to six aromatic rings (Pointing 2001).

Though many studies on microbial degradation of $\mathrm{B} a \mathrm{P}$ have been performed, literature on the effect of simultaneous existence of different pollutants groups on the extent of $\mathrm{B} a \mathrm{P}$ bioremediation is scanty. PAH contaminated sites near industrial land are often accompanied by the presence of high levels of heavy metals (Sun et al. 2010). Heavy metals may be toxic for white-rot fungi and may have a negative effect on the activity of their ligninolytic enzymes (Bamforth and Singleton 2005). Occurrence of both organic and inorganic contaminants on the same site can therefore challenge the effectiveness of bioremediation technologies (Roy et al. 2005).

Among the oxidases produced by white-rot fungi, laccases have relatively low redox potential $(0.4-0.8 \mathrm{~V})$, belong to a group of polyphenol oxidases containing copper atoms in the catalytic site and usually called multicopper oxidases (Palmer et al. 1999). Laccases are responsible for lignin degradation in nature. This enzyme lacks substrate specificity and is thus capable of degrading a wide range of non ligninolytic compounds including certain xenobiotics like industrial colored waste water, oil and oil products, chlorinated compounds and PAHs (AboState et al. 2011).

Laccase limitations, owing to their relative low redox potential, have been overcome using redox mediators like 2,2'-azinobis-(3-ethylbenzothiazoline-6-sulfonate) (ABTS) or 1-hydroxybenzotriazole (HBT) which improves the oxidation of PAHs by laccase (Johannes and Majcherczyk 2000). However, the use of these synthetic mediators makes the process expensive and may result in the development of toxic end products. In contrast, some products generated from lignin degradation could act as natural redox mediators of laccase. The use of natural compounds provides a low cost, ecofriendly and toxicity less process (Moldes et al. 2008).

Therefore the objective of the study is to evaluate the effect of heavy metals on the extent of $\mathrm{B} a \mathrm{P}$ degradation and the potential of synthetic and natural mediators to promote $\mathrm{B} a \mathrm{P}$ transformation by the native isolate, $P$. os treatus $\mathrm{PO}-3$.

\section{Materials and methods}

Chemicals and reagents

HPLC grade $\mathrm{B} a \mathrm{P}$ standard (98\% pure) was procured from Spectrochem Pvt. Ltd., Mumbai, India. Other fine chemicals used were procured from SRL Chemicals, India and were of the highest purity and analytical grade.

Effect of heavy metals and mediators

To study the effect of heavy metals and mediators on the degradation of $\mathrm{B} a \mathrm{P}(10 \mu \mathrm{g} / \mathrm{ml}$ of the mineral salt medium $)$, the PO-3 isolate of $P$. ostreatus from our previous study was used (Bhattacharya et al. 2012a). The optimized nutrients and surfactant from our earlier study were added to the modified mineral salt medium (devoid of $\mathrm{CuSO}_{4}$ and $\mathrm{MnSO}_{4}$ ) with the following composition (g/L): $\left(\mathrm{NH}_{4}\right)_{2} \mathrm{HPO}_{4}, 05 ; \mathrm{KH}_{2} \mathrm{PO}_{4}, 0.8$; $\mathrm{K}_{2} \mathrm{HPO}_{4}, 0.3 ; \mathrm{MgSO}_{4} \cdot 7 \mathrm{H}_{2} \mathrm{O}, 0.3 ; \mathrm{CaCl}_{2} \cdot 2 \mathrm{H}_{2} \mathrm{O}, 0.055$; Thiamine, $1 \mathrm{ml}(2 \mathrm{mg} / \mathrm{ml})$. The optimized physical parameters were also maintained (Bhattacharya et al. 2012b).

The effect of heavy metals and ethylenediaminetetraacetic acid (EDTA) on $\mathrm{B} a \mathrm{P}$ degradation and biomass formation was studied by incorporating salts of different heavy metals $\left(\mathrm{CuSO}_{4}, \mathrm{ZnSO}_{4}, \mathrm{MnSO}_{4}, \mathrm{AgNO}_{3}, \mathrm{CdCl}_{2}\right.$, and $\mathrm{HgCl}_{2}$ ) at $5 \mathrm{mM}$ concentration to the modified mineral salt medium. The effect of different concentrations $(5,10,15$, $20,25,30$ and $50 \mathrm{mM}$ ) of selected heavy metal salt that resulted in highest $\mathrm{B} a \mathrm{P}$ degradation and fungal growth was analyzed. ABTS and vanillin (1 and $5 \mathrm{mM}$ ) were used as mediators in the study. Broth without the heavy metals or the mediators served as the control.

Analytical methods

\section{Extraction of residual BaP}

Following incubation, the extraction of residual $\mathrm{B} a \mathrm{P}$ was performed using a modified method of Capotorti et al. (2004). The concentrated extract was subjected to high performance liquid chromatography analysis.

\section{High performance liquid chromatography analysis}

The condensed sample was subjected to filtration using $0.25 \mu$ nitrocellulose membrane filter. The working standard solution of $\mathrm{B} a \mathrm{P}$ (concentration of $5 \mu \mathrm{g} / \mathrm{ml}$ ) was prepared using 80:20 (v/v) of acetonitrile: water. $20 \mu \mathrm{l}$ of the eluate containing $0.1 \mu \mathrm{g}$ of the standard $\mathrm{B} a \mathrm{P}$ was injected 
into the HPLC system (Waters, USA, model number-2487, with dual $\lambda$ absorbance UV detector and binary pump system, model number-1525). A reverse phase, C-18 column $(150 \times 4.6 \mathrm{~mm})$ was used. The mobile phase used was acetonitrile: water $(80: 20 \mathrm{v} / \mathrm{v})$. The flow rate was maintained at $1 \mathrm{ml} / \mathrm{min}$. The concentration of the $\mathrm{B} a \mathrm{P}$ standard solution was determined at $254 \mathrm{~nm}$. Area under the absorbance peak was used to estimate the percentage of degradation using a formula:

$\left[\left(C_{\mathrm{i}}-C_{\mathrm{f}}\right) / C_{\mathrm{i}}\right]^{*} 100$, where $C_{\mathrm{i}}$ is the initial concentration of $\mathrm{B} a \mathrm{P}$ and $C_{\mathrm{f}}$ is the final concentration of $\mathrm{B} a \mathrm{P}$.

\section{Statistical analysis}

The effect of each parameter was studied in triplicate and the data are graphically presented as the mean \pm S.D. of triplicates $(n=3)$. All the graphs have been prepared using Microsoft Excel 2007.

\section{Results and discussion}

Mycoremediation refers to fungal degradation or transformation of hazardous organic contaminants to less toxic compounds (Sasek et al. 2003). P. ostreatus is a whiterot basidiomycete fungus whose ligninolytic enzyme machinery consists of laccase and manganese peroxidase. It is often considered a model organism for the degradation of xenobiotics because of its ability to colonize soil and remains unaffected by the presence of indigenous microflora, as well as its excellent performance in biodegradation studies. Several isoenzymes of laccase from $P$. ostreatus have been reported and many have been purified for their potential applications. A range of compounds, including aromatic substrates of laccase that regulate the enzyme activity is well documented (Palmieri et al. 1997).

\section{Effect of heavy metals on $\mathrm{B} a \mathrm{P}$ degradation}

Heavy metals often act as important modulators for enzyme activity. Many of these heavy metals are present in the environment either naturally $\left(\mathrm{Cu}^{2+}\right)$ or may gain their entry as a result of anthropogenic activities $\left(\mathrm{Cd}^{2+}, \mathrm{Hg}^{2+}\right.$, $\left.\mathrm{Pb}^{2+}\right)$. Polluted sites often contain high concentrations of heavy metals. Co-contamination with heavy metals may be a road block for in situ biodegradation of xenobiotics like PAHs or polychlorinated biphenyls (Koeleman et al. 1999).

Maximum degradation and biomass formation by P. ostreatus PO- 3 resulted in the presence of $\mathrm{Cu}^{2+}$ ions (71.2 \% and $63 \mathrm{mg}$ of biomass $/ 50 \mathrm{ml}$ of broth). Moderate degradation resulted from the presence of $\mathrm{Zn}^{2+}$ and $\mathrm{Mn}^{2+}$. Both biomass formation and degradation were severely

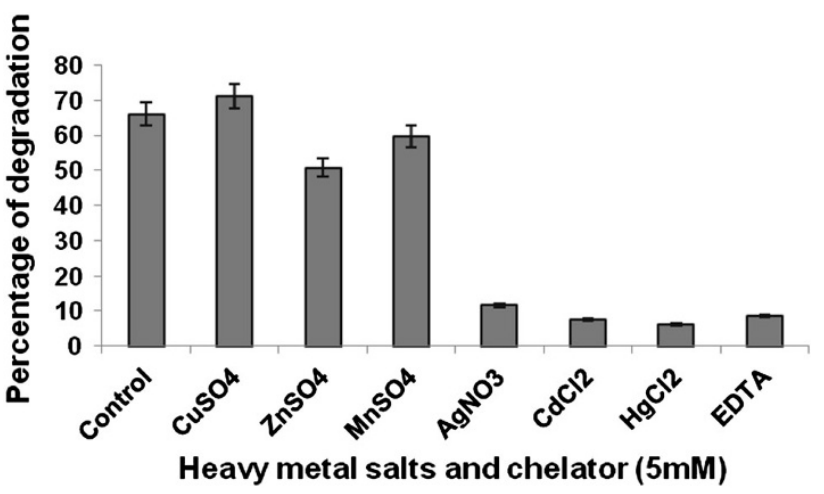

Fig. 1 Effect of heavy metal salts and chelator on degradation of $\mathrm{B} a \mathrm{P}$ by $P$. ostreatus

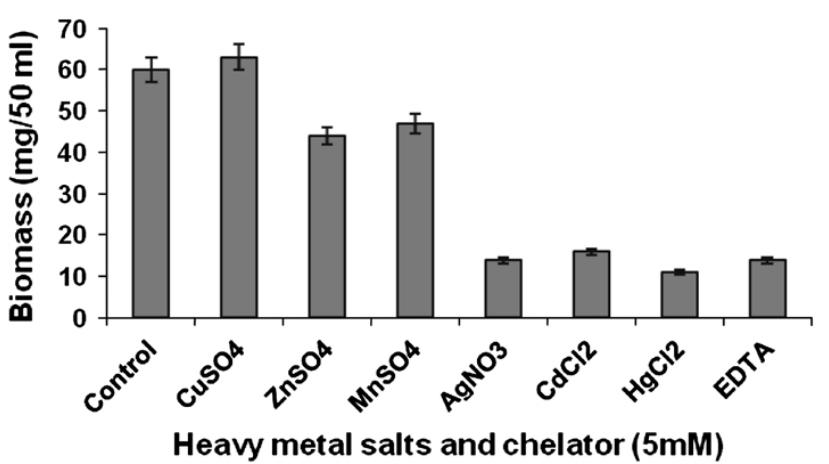

Fig. 2 Effect of heavy metal salts and chelator on P. ostreatus biomass formation

affected in the presence of $\mathrm{Ag}^{2+}, \mathrm{Cd}^{2+}, \mathrm{Hg}^{2+}$ and EDTA (Figs. 1, 2).

The present result demonstrating the increase in the extent of $\mathrm{B} a \mathrm{P}$ degradation by $P$. ostreatus $\mathrm{PO}-3$ following the addition of $\mathrm{Cu}^{2+}$ may be attributed to the increase in the laccase activity, which may in turn be due to both increased laccase production and the stabilization of the enzyme in an extracellular environment. Copper acting as a strong laccase inducer in $P$. ostreatus was reported earlier (Palmieri et al. 2000).

While characterizing the laccase from Myrothecium verrucaria NF-05, the resultant large extent activation of laccase activity in the presence of $\mathrm{Cu}^{2+}$ might be caused by the filling of type- 2 copper binding sites with $\mathrm{Cu}^{2+}$ (Sulistyaningdyah et al. 2004).

Cadmium is a non-essential heavy metal. The presence of cadmium severely affected $P$. ostreatus PO-3 biomass formation probably due to the induction of oxidative stress. $\mathrm{B} a \mathrm{P}$ degradation was also hindered by the presence of cadmium, since the sensitivity of fungi toward $\mathrm{Cu}^{2+}$ and $\mathrm{Cd}^{2+}$ changes with time. Laccase induction only occurs when cadmium is added during the later stages of growth. Parallel to our result, when cadmium was added earlier than 12 days, the activation of laccase was decreased. 
$\mathrm{Ag}^{2+}, \mathrm{Hg}^{2+}$ and $\mathrm{Pb}^{2+}$ also decreased the activity of laccase (Baldrian and Gabriel 2002). Mercury has high affinity for thiol groups in proteins, which might have lead to the inactivation of enzymes involved in the degradation (Baldrian et al. 2000).

Effect of different concentration of $\mathrm{Cu}^{2+}$ on $\mathrm{B} a \mathrm{P}$ degradation

Since copper is a biogenic metal present in the environment, its concentration may have an important role in enzyme performance and stability. Copper requirement by microorganisms is usually satisfied by very low concentrations of the metal (1-10 mM). Copper present in higher concentration proves to be extremely toxic to microbial cells (Tychanowicz et al. 2006), although reports of copper tolerance by some fungi exist (De Groot and Woodward 1999).

Result from the present study shows that greater biomass was formed in lower concentrations as compared to higher concentrations of $\mathrm{Cu}^{2+}$. Appreciable biomass and $\mathrm{B} a \mathrm{P}$ degradation were observed up to the presence of $15 \mathrm{mM}$ of $\mathrm{Cu}^{2+}$ supporting $74.2 \% \quad \mathrm{~B} a \mathrm{P}$ degradation. However, higher concentrations of copper progressively decreased biomass and $\mathrm{B} a \mathrm{P}$ degradation by $P$. ostreatus PO-3 (Fig. 3).

An early research reports similar finding, where higher $\mathrm{Cu}^{2+}$ concentration resulted in the reduced biomass formation. The probable reason for reduction in biomass formation at elevated level of $\mathrm{Cu}^{2+}$ may be attributed to the induced oxidative stress similar to that of cadmium (Baldrian et al. 2000). Similarly, Tychanowicz et al. (2006) reported that in the culture where copper was present at $10.0-25.0 \mathrm{mM}$ concentrations, laccase activity increased up to eightfold when compared to the control cultures.

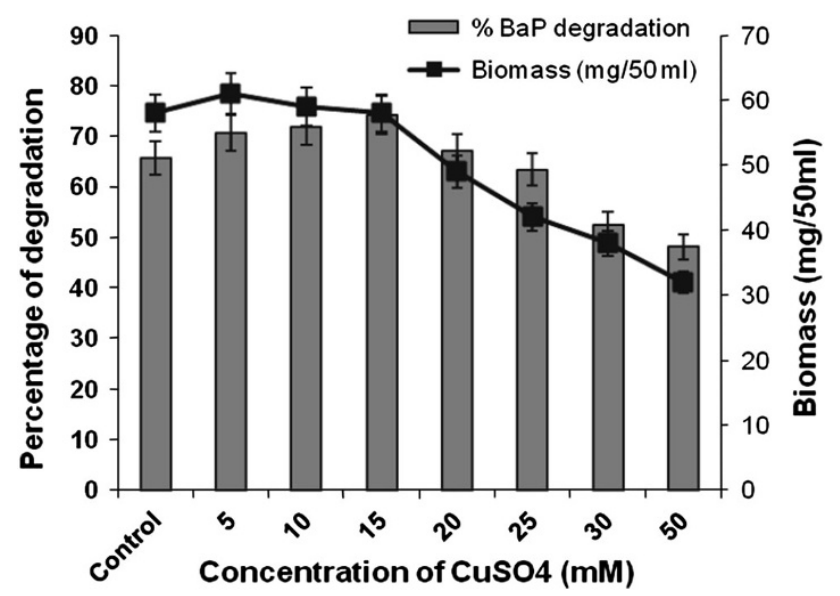

Fig. 3 Effect of different concentrations of $\mathrm{CuSO}_{4}$ on $\mathrm{B} a \mathrm{P}$ degradation and $P$. ostreatus biomass formation
Effect of mediators on $\mathrm{B} a \mathrm{P}$ degradation

It is well quoted in literature that many species of white-rot fungi, including Pleurotus sp, produce laccases that can efficiently degrade HMW PAHs such as $\mathrm{B} a \mathrm{P}$ (Juhasz and Naidu 2000). The laccase-catalyzed reaction depends on monoelectronic oxidation, which transforms the substrates to corresponding reactive radicals. With the incorporation of special compounds called mediators that act as a single electron donor and activator of the enzymes, oxidation rates of the enzyme can be enhanced (Morozova et al. 2007).

Synthetic mediators like ABTS and HBT are commonly used in degradation studies involving laccases and other lignin-modifying enzymes. Several natural phenolic compounds produced in the process of lignin depolymerization like vanillin, acetovanillone, acetosyringone, syringaldehyde, 2,4,6-trimethylphenol, $p$-coumaric acid, ferulic acid, and sinapic acid may also act as alternative mediators for the laccase mediated bioremediation of HMW PAHs by white-rot fungi (Cañas et al. 2007).

In our study, both ABTS (artificial mediator) and vanillin (natural mediator) demonstrated positive effect on the degradation as compared to that of the control (Fig. 4). ABTS proved to be superior at $1 \mathrm{mM}$ concentration (78.7\% and $42 \mathrm{mg}$ of biomass $/ 50 \mathrm{ml}$ of broth). Vanillin supported better degradation $(83.6 \%)$ at $5 \mathrm{mM}$ concentration. Both the mediators affected the biomass formation (Fig. 5).

Similar result was observed previously, wherein ligninrelated phenolic compounds acted as laccase mediators and resulted in a significant degradation of PAH. Vanillin, acetovanillone and ferulic acid significantly promoted anthracene and $\mathrm{B} a \mathrm{P}$ transformation by Pycnoporus cinnabarinus laccase (Cañas et al. 2007). The probable reason could be the structural similarities of these recalcitrant aromatic pollutants to that of lignin network.

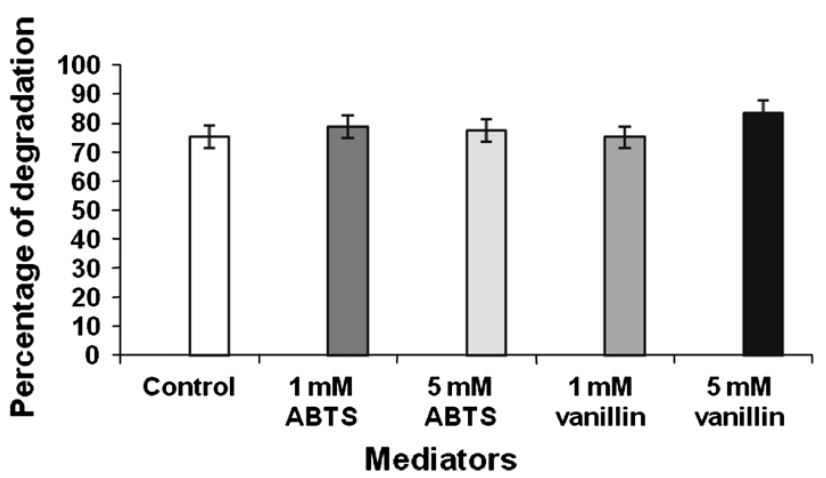

Fig. 4 Effect of ABTS and vanillin on degradation of $\mathrm{B} a \mathrm{P}$ by $P$. ostreatus 
Earlier, Pycnoporus cinnabarinus laccase without mediator oxidized only $12 \%$ of $\mathrm{B} a \mathrm{P}$ in $24 \mathrm{~h}$. The presence of the natural compounds like vanillin, acetovanillone, 2,4,6-trimethylphenol and $p$-coumaric acid notably

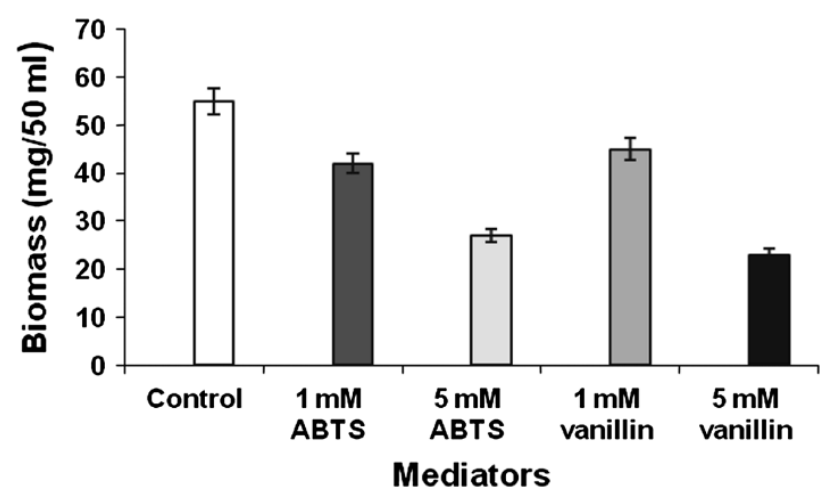

Fig. 5 Effect of ABTS and vanillin on $P$. ostreatus biomass formation promoted transformation of $\mathrm{B} a \mathrm{P}$ by laccase (Camarero et al. 2005). Positive effect has also been found by joining the artificial mediator ABTS and vanillin during pentachlorophenol transformation by laccase (Jeon et al. 2008).

Of the phenols tested, 4-hydroxybenzaldehyde and vanillin were most inhibitory to Pleurotus sajor-caju growth, and cultures supplemented with these two compounds also exhibited large increase in laccase-specific activity when compared to the unsupplemented controls (Lo et al. 2001).

Naturally occurring phenols such as syringaldehyde, vanillic acid, vanillin, and $p$-coumaric acid proved to be important laccase mediators effectively transforming cyprodinil up to $70 \%$ (Kang et al. 2002). The positive effect of the phenolic compounds derived from the lignin polymer and constituents of humic acids on the oxidative transformation of widespread pollutants such as chlorinated phenols had already been demonstrated (Park et al. 1999).
Fig. 6 HPLC chromatogram of $\mathrm{B} a \mathrm{P}$ a control, b after degradation

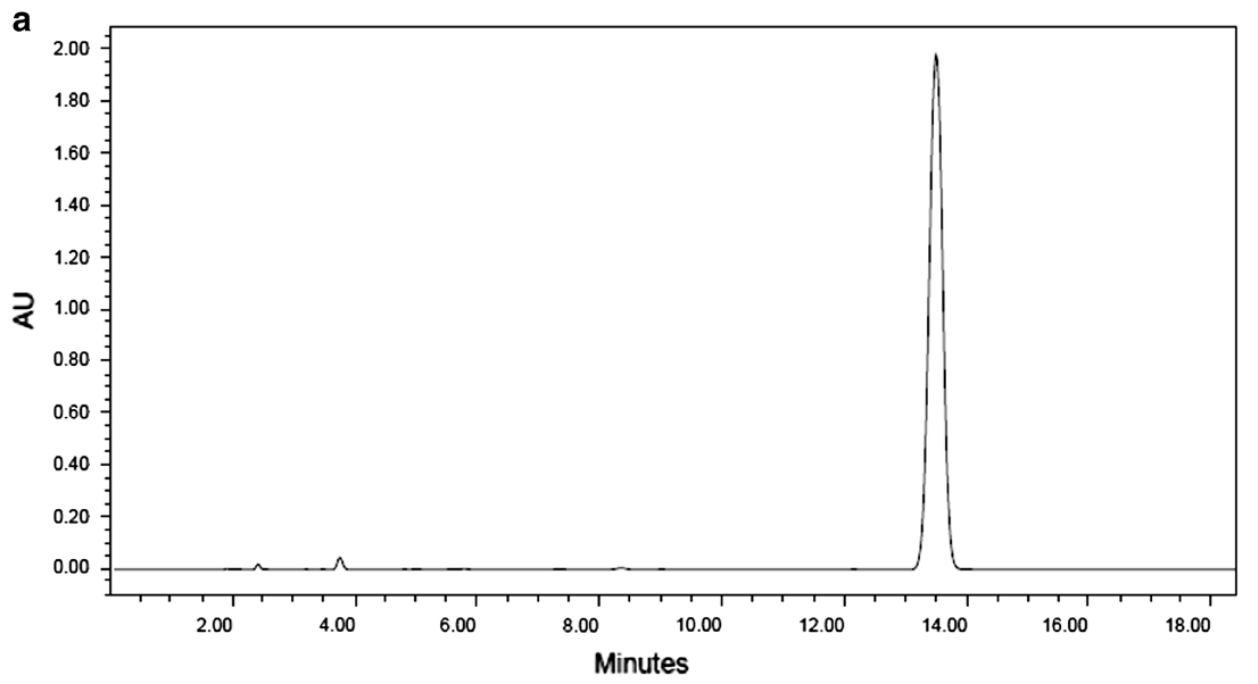

b

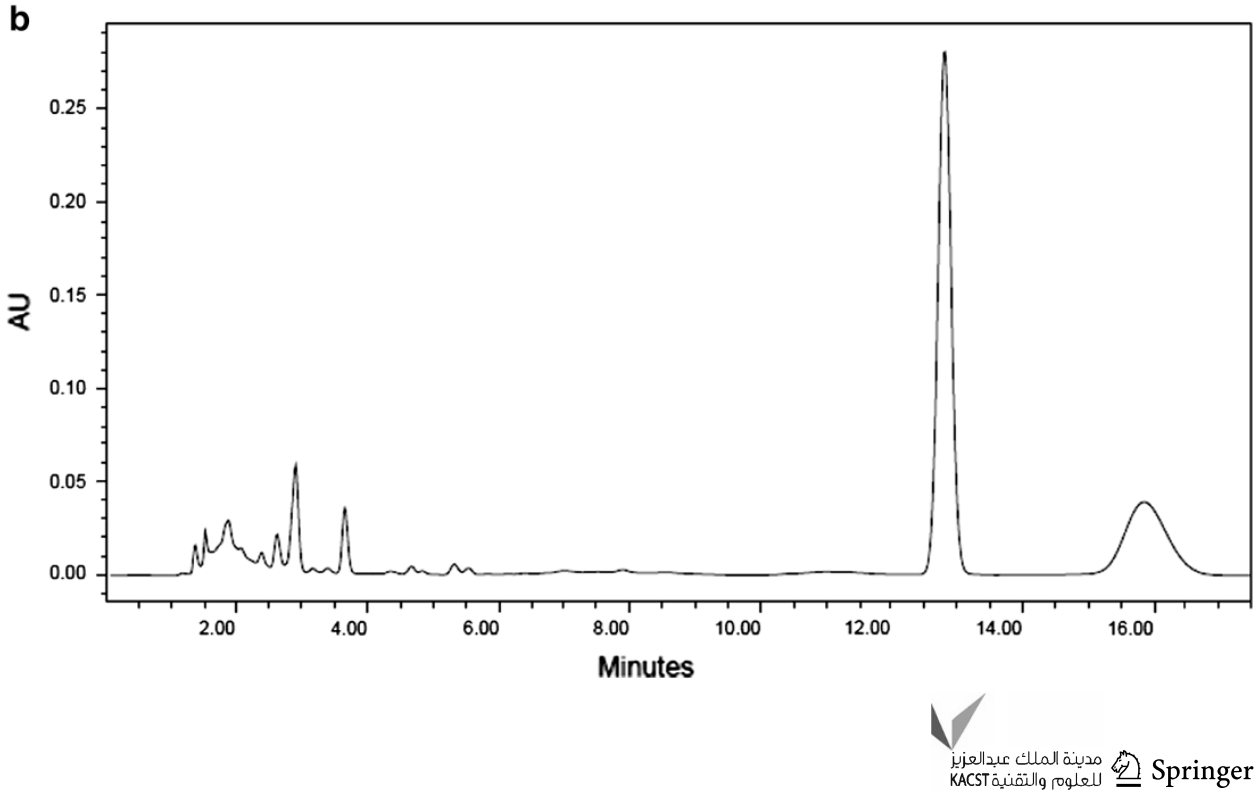


HPLC analysis reveals biodegradation of $\mathrm{B} a \mathrm{P}$ by $P$. ostreatus PO-3 under optimized media and growth conditions (Fig. 6a, b).

\section{Conclusions}

Various metals may be present in a contaminated site alongside the PAHs. The results showed varied levels of $\mathrm{B} a \mathrm{P}$ degradation in the presence of heavy metals. Improved biodegradation in case of copper availability can be correlated to the activation and stabilization of the produced laccase by $P$. ostreatus PO-3.

Natural mediators may play an important role in the degradation of $\mathrm{PAH}$ by white-rot fungi. In future, ligninderived mediator like vanillin may act as an alternative to synthetic mediator like ABTS. Besides improving the working potential of the ligninolytic enzymes, these natural mediators are released in large amount as a result of the microbial degradation of lignocellulose and are present in humus as common secondary plant metabolites. Vanillin and similar mediators would thus effectively reduce the cost of the bioremediation process.

Acknowledgments We wish to extend our sincere gratitude to the managements of Karpagam University, Jain University and Bharathiar University for their encouraging support. Our special thanks to Dr. R. Chenraj Jain, Chairman of Jain Group of Institutions, Dr. N. Sundararajan, Vice-Chancellor of Jain University and Dr. S. Sundara Rajan, Director of Genohelix Biolabs, A Division of Centre for Advanced Studies in Biosciences, Jain University, Bangalore for providing us with the laboratory facilities required for this research work.

Conflict of interest The authors declare that they have no conflict of interest.

Open Access This article is distributed under the terms of the Creative Commons Attribution License which permits any use, distribution, and reproduction in any medium, provided the original author(s) and the source are credited.

\section{References}

Abo-State MAM, Khatab O, Abo-El Nasar A, Mahmoud B (2011) Factors affecting laccase production by Pleurotus ostreatus and Pleurotus sajor-caju. World Appl Sci J 14:1607-1619

Baldrian P, Gabriel J (2002) Copper and cadmium increase activity in Pleurotus ostreatus. FEMS Microbiol Lett 206:69-74

Baldrian P, Der Weische CW, Gabriel J, Nerud F, Zadrazil F (2000) Influence of cadmium and mercury on activities of ligninolytic enzymes and degradation of polycyclic aromatic hydrocarbons by Pleurotus ostreatus in soil. Appl Environ Microbiol 66:2471-2478

Bamforth SM, Singleton I (2005) Bioremediation of polycyclic aromatic hydrocarbons: current knowledge and future directions. J Chem Technol Biotechnol 80:723-736
Bhattacharya S, Angayarkanni J, Das A, Palaniswamy M (2012a) Mycoremediation of Benzo[a]pyrene by Pleurotus ostreatus isolated from Wayanad district in Kerala, India. Int J Pharm Bio Sci 2:84-93

Bhattacharya S, Angayarkanni J, Das A, Palaniswamy M (2012b) Evaluation of physical parameters involved in mycoremediation of Benzo[a]pyrene by Pleurotus ostreatus. J Pure Appl Microbio 6:1721-1726

Camarero S, Ibarra D, Martínez MJ, Martínez AT (2005) Ligninderived compounds as efficient laccase mediators for decolorization of different types of recalcitrant dyes. Appl Environ Microbiol 71:1775-1784

Cañas A, Alcalde M, Plou FJ, Martínez MJ, Martínez AT, Camarero S (2007) Transformation of polycyclic aromatic hydrocarbons by laccase is strongly enhanced by phenolic compounds present in soil. Environ Sci Technol 41:2964-2971

Capotorti G, Digianvincenzo P, Cesti P, Bernardi A, Guglielmetti G (2004) Pyrene and benzo(a)pyrene metabolism by an Aspergillus terreus strain isolated from a polycyclic aromatic hydrocarbons polluted soil. Biodegradation 15:79-85

Chatterjee S, Chattopadhyay P, Roy S, Sen SK (2008) Bioremediation: a tool for cleaning polluted environments. J Appl Biosci 11:594-601

De Groot RC, Woodward BM (1999) Using copper-tolerant fungi to biodegrade wood treated with copper-based preservatives. Int Biodeterior Biodegrad 44:17-27

Jeon JR, Murugesan K, Kim YM, Kim EJ, Chang YS (2008) Synergistic effect of laccase mediators on pentachlorophenol removal by Ganoderma lucidum laccase. Appl Microbiol Biotechnol 81:783-790

Johannes C, Majcherczyk A (2000) Natural mediators in the oxidation of polycyclic aromatic hydrocarbons by laccase mediator systems. Appl Environ Microbiol 66:524-528

Juhasz AL, Naidu R (2000) Bioremediation of high molecular weight polycyclic aromatic hydrocarbons: a review of the microbial degradation of benzo $[a]$ pyrene. Int Biodeterior Biodegrad 45:57-88

Kang KH, Dec J, Park H, Bollag JM (2002) Transformation of the fungicide cyprodinil by a laccase of Trametes villosa in the presence of phenolic mediators and humic acid. Water Res 36:4907-4915

Koeleman M, Vd Laak JW, Ietswaart H (1999) Dispersion of PAH and heavy metals along motorways in the Netherlands-an overview. Sci Total Environ 235:347-349

Li Z, Sjodin A, Porter EN, Patterson DGJ, Needham LL, Lee S, Russell AG, Mulholland JA (2009) Characterization of $\mathrm{PM}_{2.5^{-}}$ bound polycyclic aromatic hydrocarbons in Atlanta. Atmos Environ 43:1043-1050

Lo SC, Ho YS, Buswell JA (2001) Effect of phenolic monomers on the production of laccases by the edible mushroom Pleurotus sajor-caju, and partial characterization of a major laccase component. Mycologia 93:413-421

Moldes D, Diaz M, Tzanov T, Vidal T (2008) Comparative study of the efficiency of synthetic and natural mediators in laccaseassisted bleaching of eucalyptus kraft pulp. Bioresour Technol 99:7959-7965

Morozova OV, Shumakovich GP, Shleev SV, Yaropplov YI (2007) Laccase-mediator systems and their applications: a review. Appl Biochem Microbiol 43:523-535

Palmer AE, Randall DW, Xu F, Solomon EI (1999) Spectroscopic studies and electronic structure description of the high potential type 1 copper site in fungal laccase: insight into the effect of the axial ligand. J Am Chem Soc 121:7138-7149

Palmieri G, Giardina P, Bianco C, Scaloni A, Capasso A, Sannia G (1997) A novel white laccase from Pleurotus ostreatus. J Biol Chem 272:31301-31307 
Palmieri G, Giardina P, Bianco C, Fontanella B, Sannia G (2000) Copper induction of laccase isoenzymes in the ligninolytic fungus Pleurotus ostreatus. Appl Environ Microbiol 66: 920-924

Park JW, Dec J, Kim JE, Bollag JM (1999) Effect of humic constituents on the transformation of chlorinated phenols and anilines in the presence of oxidoreductive enzymes or birnessite. Environ Sci Technol 33:2028-2034

Pointing SB (2001) Feasibility of bioremediation by white-rot fungi. Appl Microbiol Biotechnol 57:20-33

Rentz JA, Alvarez PJJ, Schnoor JL (2008) Benzo[a]pyrene degradation by Sphingomonas yanoikuyae JAR02. Environ Pollut 151:669-677

Roy S, Labelle S, Mehta P, Mihoc A, Fortin N, Masson C, Leblanc R, Châteauneuf G, Sura C, Gallipeau C, Olsen C, Delisle S, Labrecque M, Greer CW (2005) Phytoremediation of heavy metal and PAH contaminated brownfield sites. Plant Soil 272:277-290

Sasek V, Cajthaml T, Bhatt M (2003) Use of fungal technology in soil remediation: a case study. Water Air Soil Pollut Focus 3:5-14

Sulistyaningdyah W, Ogawa J, Tanaka H, Maeda C, Shimizu S (2004) Characterization of alkaliphilic laccase activity in the culture supernatant of Myrothecium verrucaria $24 \mathrm{G}-4$ in comparison with bilirubin oxidase. FEMS Microbiol Lett 230:209-215

Sun F, Wen D, Kuang Y, Li J, Li J, Zuo W (2010) Concentrations of heavy metals and polycyclic aromatic hydrocarbons in needles of Masson pine (Pinus massoniana L.) growing nearby different industrial sources. J Environ Sci 22:1006-1013

Tychanowicz GK, de Souza DF, Souza CGM, Kadowaki MK, Peralta RM (2006) Copper improves the production of laccase by the white-rot fungus Pleurotus pulmonarius in solid state fermentation. Braz Arch Biol Technol 49:699-704 